JKEP

Vol 4, No 1, Mei 2019

ISSN: 2354-6042 (Print)

ISSN : 2354-6050 (Online)

\title{
Efektivitas Pemberian Oksigen Posisi Semi Fowler Dan Fowler Terhadap Perubahan Saturasi Pada Pasien Asma Bronkial Persisten Ringan
}

\author{
Syamsul Firdaus, Misbachul Munirul Ehwan, Agus Rachmadi \\ Poltekkes Kemenkes Banjarmasin \\ Email : syamsulfirdaus1966@gmail.com
}

\author{
Artikel history \\ Dikirim, Feb 20 $0^{\text {th }}, 2019$ \\ Ditinjau, April 12 $2^{\text {th }}, 2019$ \\ Diterima, April 30 ${ }^{\text {th }}, 2019$
}

\begin{abstract}
Mild persistent bronchial asthma is a chronic inflammatory airway that cause the low oxygen saturation value (91-95\%). Administering oxygen therapy, setting the position of the semi fowler and fowler can reduce the risk of a decreased chest configuration. This research aims to assess the difference of effectiveness of administering oxygen at semi fowler with fowler position to the saturation changes in mild persistent bronchial asthma patients in Ratu Zalecha Martapura Hospital. This research method is quasy Experiment. The population research are all patients who experience mild persistent bronchial asthma attack, the sample of this research are 20 respondents with purposive sampling technique and analyzed with independent $T$ test. The results is at semi fowler position the average of oxygen saturation before the treatment is $93.10 \%$, after administering oxygen therapy with semi fowler position the average saturation is $98.00 \%$. At the fowler position the average of oxygen saturation before the treatment is $92.60 \%$, after administering oxygen therapy with fowler position the average saturation is $98.00 \%$. The independent T-test result showed no difference of effectiveness of administering oxygen at semi fowler with fowler position to the saturation changes in mild persistent bronchial asthma patients, so teh patients can be given both positions.
\end{abstract}

Keywords : Bronchial Asthma, Oxygen, Client positions, Saturation

\begin{abstract}
Abstrak
Asma bronkial persisten ringan merupakan inflamasi kronik jalan napas yang menyebabkan rendahnya nilai saturasi oksigen (91-95\%). Pemberian terapi oksigen, pengaturan posisi semi fowler dengan fowler dapat mengurangi risiko penurunan pengembangan dinding dada. Penelitian ini bertujuan menilai perbedaan efektivitas pemberian oksigen pada posisi semi fowler dengan fowler terhadap perubahan saturasi pada pasien asma bronkial persisten ringan di RSUD Ratu Zalecha Martapura. Metode penelitian ini eksperimental dengan rancangan Quasy Experiment. Populasi dalam penelitian ini seluruh pasien yang mengalami serangan asma bronkial persisten ringan sebanyak 30 orang, sampel dalam penelitian sebanyak 20 orang dengan teknik Purposive sampling, dianalisis dengan uji $\mathrm{T}$ independen. Hasil penelitian pada posisi semi fowler rata-rata saturasi oksigen sebelum sebesar $93.10 \%$, setelah pemberian terapi oksigen
\end{abstract}


dengan posisi semi fowler sebesar $98.00 \%$. Pada posisi fowler rata-rata saturasi oksigen sebelum $92.60 \%$, setelah pemberian terapi oksigen dengan posisi fowler sebesar 98.00 $\%$. Hasil uji $\mathrm{T}$ Independen menunjukkan tidak ada perbedaan efektivitas pemberian oksigen pada posisi semi fowler dengan fowler terhadap perubahan saturasi pada pasien asma bronkial Persisten Ringan di IGD RSUD Ratu Zalecha Martapura. Pasien yang mengalami asma bronkial persisten ringan dapat diberikan kedua posisi.

Kata Kunci : Asma bronkial, Oksigen, Posisi klien, Saturasi

\section{PENDAHULUAN}

Menurut Global Initiatif for Asthma, asma merupakan masalah kesehatan di seluruh dunia, baik di negara maju maupun di negara-negara yang sedang berkembang. Penyakit ini adalah penyakit heterogen yang ditandai inflamasi kronik saluran napas, dengan gejala sesak napas, mengi, dada terasa berat, batuk semakin memberat dan keterbatasan aliran udara ekspirasi (Mark, et all, 2016).

Berdasarkan data World Health

Organization (WHO) tahun 2011 menyebutkan bahwa terdapat 235 juta orang menderita asma di dunia, $80 \%$ berasal dari negara dengan pendapatan rendah hingga menengah, termasuk Indonesia. Berdasarkan data Sistem Informasi Rumah Sakit (SIRS), di Indonesia didapatkan bahwa angka kematian akibat penyakit asma adalah sebanyak 63.584 orang (Pangestu, dkk, 2016). Menurut data Riset Kesehatan Dasar (Riskesdas) tahun 2013 menyatakan bahwa prevalensi asma semua umur di Indonesia mencapai angka 4,5\%
(11.196.000 jiwa), sedangkan di Provinsi Kalimantan Selatan mencapai angka 6,3\% (242.834 jiwa) (Balitbang, 2013).

Asma merupakan suatu penyakit peradangan kronis pada saluran pernapasan dengan karakteristik berupa hipersensitivitas, edema mukosa dan produksi mukus (Smeltzer, et al, 2010). Hal ini dapat menyebabkan peradangan dan penyempitan yang sifatnya berulang namun reversible (Price dan Wilson, 2006).

Organ-organ dalam tubuh membutuhkan suplai oksigen yang cukup agar fungsinya lebih optimal dan efektif. Jika nilai saturasi oksigen rendah, berbagai masalah kesehatan dapat terjadi diantaranya terjadi hipoksemia (Musliha, 2010). Hipoksia merupakan keadaan kekurangan oksigen di jaringan atau tidak adekuatnya pemenuhan kebutuhan oksigen seluler akibat defisiensi oksigen yang diinspirasi atau meningkatnya penggunaan oksigen pada tingkat seluler. Hipoksemia ditandai dengan sesak napas, frekuensi napas 35 
kali/menit, nadi cepat dan dangkal, serta sianosis (Tarwoto dan Watonah, 2010).

Salah satu tindakan untuk mengurangi risiko kejadian hipoksemia adalah terapi oksigen. Terapi oksigen bertujuan untuk mengoreksi hipoksemia (kadar oksigen dalam darah rendah) dengan cara memperbaiki hipoksemia, dan menurunkan kerja pernapasan (Morton, dkk, 2012). Pada pasien yang mengalami serangan asma bronkial, dapat mengakibatkan timbulnya gejala seperti sesak napas, nafas cepat (> 24 kali permenit) dan dada terasa berat. Dengan adanya manifestasi klinis sesak serta dada terasa berat, pasien asma diindikasikan untuk mendapatkan terapi oksigen (Setyohadi, dkk, 2015).

Efek pemberian terapi oksigen dapat dilihat melalui nilai saturasi oksigen. Saturasi oksigen merupakan kemampuan hemoglobin mengikat oksigen yang ditujukan sebagai derajat kejenuhan atau saturasi ( $\mathrm{SaO} 2)$ (Wahyuningsih, 2015). Pulse oximetri merupakan alat non-invasif yang digunakan untuk memperkirakan saturasi oksigen darah arteri klien dengan cara mendekatkan sensor pada jari tangan, jari kaki, hidung, cuping telinga, atau dahi (sekitar tangan atau kaki pada neonatus) (Kozier dan Erb's, 2016).

Metode yang paling sederhana untuk mengurangi risiko penurunan pengembangan dinding dada yaitu dengan pengaturan posisi saat istirahat. Posisi fowler merupakan posisi tempat tidur dimana posisi kepala dan tubuh ditinggikan $45^{\circ}$ hingga $60^{\circ}$ dimana posisi lutut mungkin/mungkin tidak dalam posisi tertekuk, sedangkan posisi semi fowler merupakan posisi tempat tidur dimana posisi kepala dan tubuh ditinggikan $15^{\circ}$ hingga $45^{\circ}$. Posisi ini biasanya disebut dengan fowler rendah dan biasanya ditinggikan setinggi $30^{\circ}$ (Kozier dan Erb's, 2016).

Menurut penelitian yang dilakukan oleh Sucahyono, W. (2012) menunjukkan bahwa rata-rata kenaikan saturasi oksigen pada posisi semi fowler yaitu $2.87 \%$ dan rata-rata kenaikan saturasi pada posisi fowler yaitu $4.99 \%$ (Sucahyono, 2012). Rumusan masalah dalam penelitian ini adalah apakah ada perbedaan efektivitas pemberian oksigen pada posisi semi fowler dengan fowler terhadap perubahan saturasi pada pasien asma bronkial persisten ringan di IGD RSUD Ratu Zalecha Martapura?

\section{METODE}


Penelitian ini bersifat kuantitatif dengan jenis penelitian yang digunakan eksperimental dan rancangan penelitan Quasy Experiment yaitu jenis penelitan yang bertujuan untuk mengungkapkan hubungan sebab akibat dengan cara melibatkan kelompok kontrol di samping kelompok eksperimental (Nursalam, 2015).

Populasi dalam penelitian ini adalah seluruh pasien yang mengalami serangan asma bronkial yang masuk di IGD RSUD Ratu Zalecha Martapura dengan kisaran 30 pasien per bulan (Juni 2016). Sampel yang diteliti sebanyak 20 pasien asma bronkial persisten ringan yang berobat ke IGD Rumah Sakit Umum Daerah Ratu Zalecha Martapura. Teknik sampling dalam penelitian ini adalah dengan menggunakan teknik non-probability sampling dengan cara Purposive sampling yang dibagi menjadi 10 sampel untuk kelompok intervensi dan 10 sampel untuk kelompok control. Pemilihan kelompok intervensi adalah 10 pasien pertama yang datang ke IGD sedangkan kelompok kontrol adalah Pengumpulan data dilakukan secara primer dan sekunder. Secara primer diperoleh dari hasil observasi selama 15 menit pada saat pasien yang mendapat serangan asma bronkhial persisten ringan datang berobat ke ruang IGD RSUD Ratu Zalecha Martapura selama Juni (2016), sedangkan secara sekunder diperoleh dari laporan tahunan Instalasi Rekam. Instrumen yang digunakan pada penelitian ini adalah observasi, dalam tabel tersebut tercatat karakteristik responden dan saturasi oksigen sebelum dan sesudah pemberian posisi semi fowler dengan fowler pada pemberian terapi oksigen nasal kanul, untuk pengukuran nilai saturasi oksigen menggunakan pulse oximetry.

Analisa data yaitu analisa univariat dan analisa bivariat menggunakan uji Independent sample $t$ Test, penggunaan rumus ini adalah untuk menguji efektifitas suatu perlakuan terhadap suatu besaran variabel yang ingin ditentukan (Dahlan, 2011).

10 pasien berikutnya yang datang ke IGD.

\section{HASIL DAN PEMBAHASAN}

1. Pemberian Oksigen pada Posisi Semi Fowler terhadap Perubahan Saturasi pada Pasien Asma Bronkial Persisten Ringan di IGD RSUD Ratu Zalecha Martapura 
Gambar 6.1 Nilai saturasi sebelum dan sesuah pemberian oksigen pada posisi semi fowler

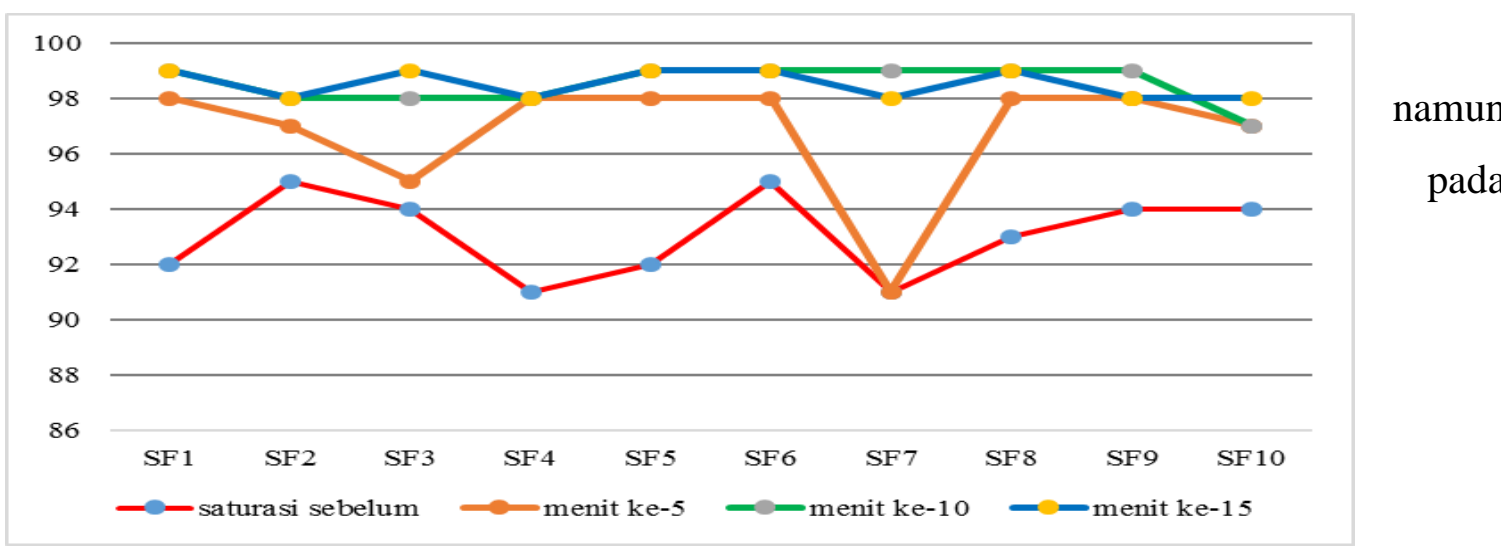

Berdasarkan gambar 6.1 terlihat bahwa responden SF3 dan SF 7 tidak mengalami rata-rata saturasi oksigen dari 10 responden peningkatan yang signifikan.

saat datang ke IGD sekitar $93.10 \%$, setelah pemberian terapi oksigen dengan posisi Kondisi ini terjadi adanya kontribusi faktor semi fowler nilai rata-rata saturasi lain, seperti aktivitas (pergerakan yang meningkat menjadi $98.00 \%$. Pada grafik berlebihan pada area sensor oksimetri) scatter di atas menunjukkan adanya sehingga memengaruhi hasil pembacaan peningkatan nilai saturasi oksigen pada saturasi. Menurut Kozier \& Erb's (2016) setiap responden pada saat sebelum dan bahwa hemoglobin, sirkulasi, aktivitas, dan sesudah diberikan terapi oksigen dengan keracunan karbon monoksida pengaturan posisi semi fowler.

memengaruhi Hasil pembacaan saturasi oksigen. Pada menit ke-10 dan ke-15, nilai Pada saat sebelum pemberian oksigen dan saturasi tiap responden terlihat relatif sama, pengaturan posisi, terlihat pada grafik nilai dengan rata-rata saturasi pada menit kesaturasi responden bervariasi, yaitu 210 dan ke-15 sebesar 98.50\% (Kozier dan responden dengan saturasi 91\%, 2 Erb's, 2016). responden dengan saturasi 92\%, 1 responden dengan saturasi 93\%, 3 Peningkatan yang signifikan. responden dengan saturasi 94\%, dan 2 Menurut peneliti, kemungkinan hal ini responden dengan saturasi 95\%. Pada disebabkan oleh faktor lain, seperti grafik menit ke-5 terlihat nilai saturasi aktivitas (seperti pergerakan yang masing-masing responden meningkat, berlebihan pada area sensor oksimetri) 
sehingga memengaruhi hasil pembacaan saturasi.

Menurut Kozier \& Erb's (2016) bahwa hemoglobin, sirkulasi, aktivitas, dan keracunan karbon monoksida memengaruhi hasil pembacaan saturasi oksigen. Pada menit ke-10 dan ke-15, nilai saturasi tiap responden terlihat relative sama, dengan rata-rata saturasi pada menit ke-10 dan ke-15 sebesar 98.50\% (Kozier dan Erb's , 2016).

Pemberian terapi oksigen pada pasien bertujuan untuk mengoreksi hipoksemia (kadar oksigen yang rendah dalam darah). Terapi oksigen memperbaiki hipoksemia, menurunkan kerja pernapasan, dan mengurangi kerja miokardium (Morton, dan pemberian terapi oksigen. dkk, 2012). Pengaturan posisi merupakan salah satu cara untuk mengurangi rasa sesak pada pasien asma bronkial. Tujuan pemberian posisi semi fowler adalah membantu mengatasi masalah kesulitan pernapasan dan pasien dengan gangguan jantung (Suparmi, dkk, 2008).

Hasil penelitian terkait nilai saturasi pada pemberian oksigen sebelum dan sesudah pengaturan posisi semi fowler pada pasien asma bronkial persisten ringan menghasilkan peningkatan saturasi oksigen dengan rata-rata saturasi oksigen $\left(\mathrm{SpO}_{2}\right) \quad 93.10 \%$ sebelum dilakukan pengaturan posisi semi fowler dan pemberian terapi oksigen dan $98 \%$ setelah dilakukan pengaturan posisi semi fowler

Gambar 6.3 Grafik Perbandingan Nilai Saturasi Oksigen Responden Sebelum dan Sesudah pemberian oksigen dengan Pengaturan Posisi Semi Fowler dengan Fowler pada Pasien Asma Bronkial Persisten Ringan di IGD RSUD Ratu Zalecha Martapura

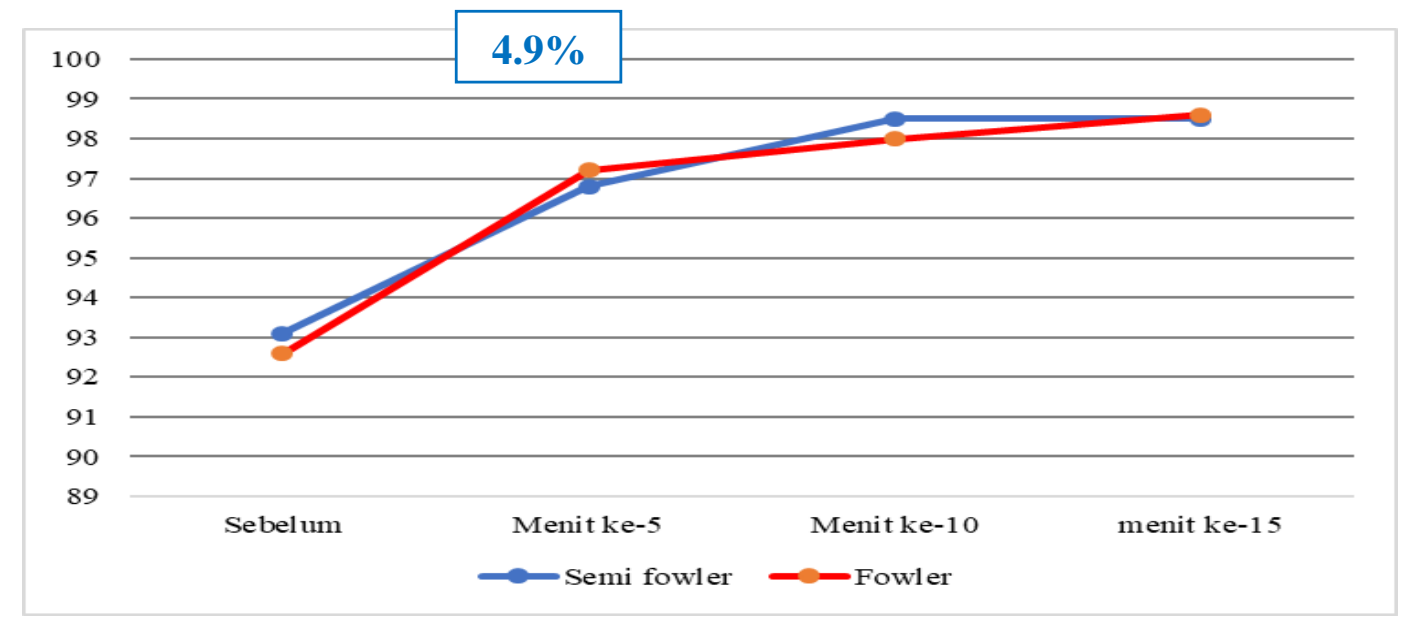

2. Pemberian Oksigen pada Posisi Fowler terhadap Perubahan Saturasi pada Pasien Asma Bronkial Persisten Ringan di IGD RSUD Ratu Zalecha Martapura 
Gambar 6.2 Nilai saturasi sebelum dan sesuah pemberian oksigen pada posisi fowler

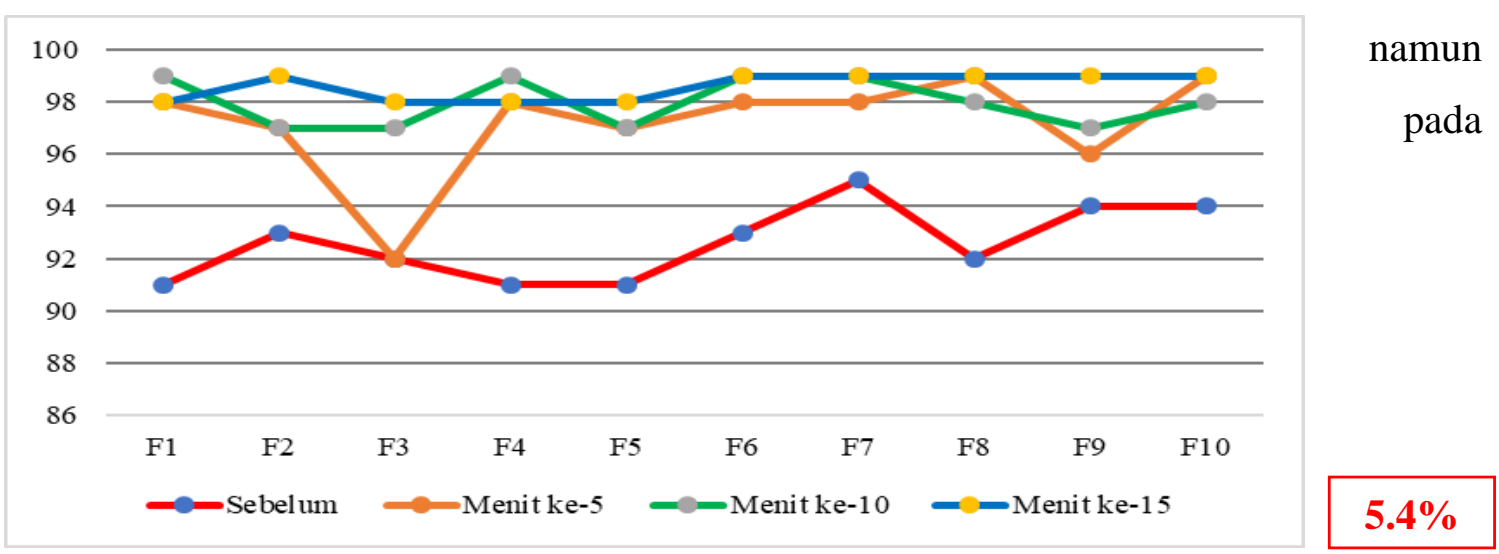

Berdasarkan gambar 6.2 terlihat bahwa responden F3 dan SF 9 tidak mengalami rata-rata saturasi oksigen dari 10 responden peningkatan yang signifikan.

saat datang ke IGD sekitar $92.60 \%$, setelah pemberian terapi oksigen dengan posisi Kondisi ini terjadi adanya kontribusi faktor fowler nilai rata-rata saturasi meningkat menjadi $98.00 \%$.

lain, seperti nilai Hemoglobin, aktivitas (seperti pergerakan yang berlebihan pada area sensor oksimetri) sehingga

Pada grafik tersebut menunjukkan adanya memengaruhi hasil pembacaan saturasi. peningkatan nilai saturasi oksigen pada Hal ini sesuai dengan teori di dalam buku setiap responden pada saat sebelum dan Kozier \& Erb's (2016) bahwa haemoglobin, sesudah diberikan terapi oksigen dengan pengaturan posisi fowler.

sirkulasi, aktivitas, dan keracunan karbon monoksida memengaruhi hasil pembacaan saturasi oksigen pada menit ke-10 nilai Pada saat sebelum pemberian oksigen dan pengaturan posisi, terlihat pada grafik nilai saturasi tiap responden sebesar $98.00 \%$ dan pada menit ke-15 sebesar $98.60 \%$ (Kozier saturasi responden bervariasi, yaitu 3 dan Erb's , 2016). responden dengan saturasi 91\%, 2 responden dengan saturasi 92\%, 2 Pengaturan posisi merupakan salah satu responden dengan saturasi 93\%, 2 cara untuk mengurangi rasa sesak pada responden dengan saturasi 94\%, dan 1 pasien asma bronkial. Posisi fowler responden dengan saturasi 95\%. Pada bertujuan untuk mempertahankan grafik menit ke-5 terlihat nilai saturasi kenyamanan dan memfasilitasi fungsi masing-masing responden meningkat, sehingga meningkatnya ekspansi dada dan ventilasi paru serta menurunkan upaya 
pernapasan (Hidayat, 2008 dan

Doengoes,et all, 2010).

3. Analisis Perbedaan Efektivitas Pemberian Oksigen pada Posisi Semi Fowler dengan Fowler terhadap Perubahan Saturasi pada Pasien Asma Bronkial Persisten Ringan di IGD RSUD Ratu Zalecha Martapura

Hasil analisis menggunakan uji $\mathrm{t}$ signifikan baik pada posisi semi fowler independen pada pemberian oksigen pada maupun fowler.

posisi semi fowler dengan fowler pada pasien asma bronkial di IGD RSUD Ratu Zalecha Martapura menunjukkan tidak ada perbedaan efektivitas pemberian oksigen pada posisi semi fowler dengan fowler terhadap perubahan saturasi pada pasien asma bronkial persisten ringan. Nilai $t$ hitung berdasarkan uji t-independen yaitu 0.000, sedangkan nilai t tabel sebesar 2,101. Nilai $P$ value berdasarkan uji t-independen yaitu 1.000, sehingga dapat disimpulkan jika nilai t hitung $<\mathrm{t}$ tabel $(0.000<2.101)$ dan $\mathrm{P}$ value $(1.000>0.05)$ maka $\mathrm{Ho}$ diterima.

Pada gambar 6.3 menunjukkan nilai ratarata peningkatan saturasi oksigen sebelum dan sesudah pemberian oksigen dengan pengaturan posisi semi fowler dengan fowler pada pasien asma bronkial persisten ringan di IGD RSUD Ratu Zalecha Martapura. Pada grafik tersebut terlihat tidak adanya perbedaan nilai saturasi yang

Rata-rata kenaikan saturasi oksigen pada posisi semi fowler yaitu $4.9 \%$, sedangkan rata-rata kenaikan saturasi oksigen pada posisi fowler yaitu $5.4 \%$, sehingga tidak ada perbedaan nilai saturasi antara posisi semi fowler dengan fowler. Hal ini sesuai dengan penelitian yang dilakukan oleh Sucahyono, W. tahun 2012 dengan judul "Identifikasi Penempatan Posisi terhadap Saturasi Oksigen pada Pasien Penyakit Paru Obstruksi Kronis di Ruang Dahlia Rumah Sakit Paru dr. Ario Wirawan Salatiga" yang menunjukkan bahwa ratarata kenaikan saturasi oksigen pada posisi semi fowler yaitu $2.87 \%$ dan rata-rata kenaikan saturasi pada posisi fowler yaitu $4.99 \%$ (Sucahyono, 2012).

Hasil penelitian menunjukkan tidak ada perbedaan efektivitas antara pemberian oksigen pada posisi semi fowler dengan fowler terhadap Perubahan Saturasi pada 
Pasien Asma Bronkial di IGD RSUD Ratu yaitu faktor usia, jenis kelamin, nutrisi, Zalecha Martapura. Pada prinsipnya ekspansi paru serta cara pemberian oksigen oksigen dipengaruhi oleh beberapa faktor,

\section{a. Faktor Usia}

Gambar 6.4 Grafik Karakteristik Responden Berdasarkan Umur Pasien Asma Bronkial Persisten ringan di IGD RSUD Ratu Zalecha Martapura

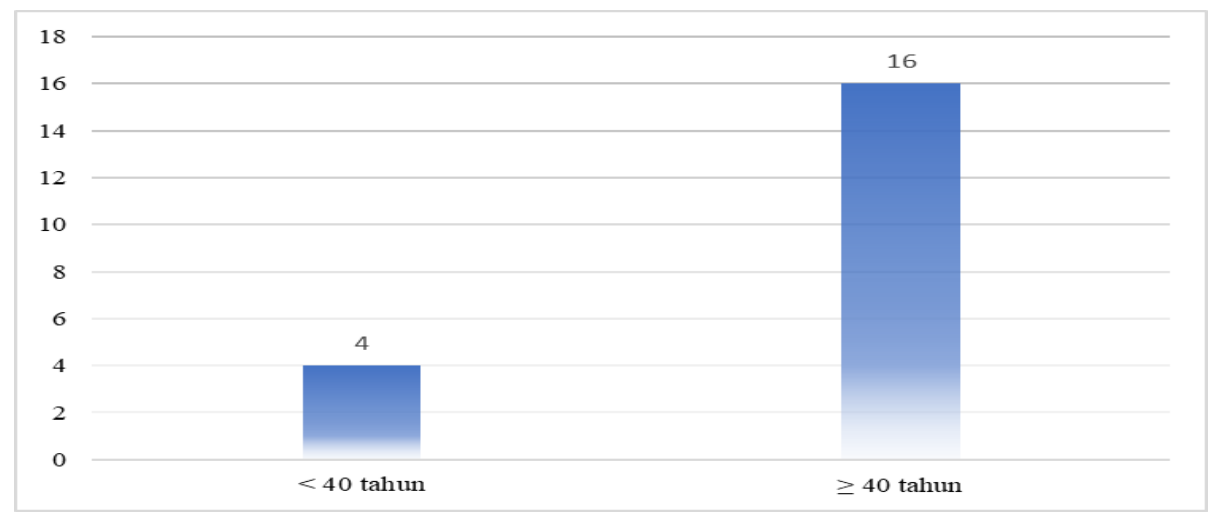

Menurut RISKESDAS (2007) data penelitian dan teori yang ada, dapat kita prevalensi asma berdasarkan karakteristik simpulkan bahwa usia merupakan salah umur menunjukkan angka kejadian asma satu faktor dari kejadian asma bronkial. pada usia 40 - 60 tahun sebesar $4.8 \%$, Hal ini dikarenakan semakin sedangkan pada usia 20 - 39 tahun sebesar bertambahnya usia, maka fungsi paru akan $2.8 \%$ (Balitbang, 2007). Berdasarkan hasil menurun (Cardova, et al, 2011).

\section{b. Faktor Jenis Kelamin}

Gambar 6.5 Grafik Karakteristik Responden Berdasarkan Jenis Kelamin Pasien Asma Bronkial Persisten ringan di IGD RSUD Ratu Zalecha Martapura

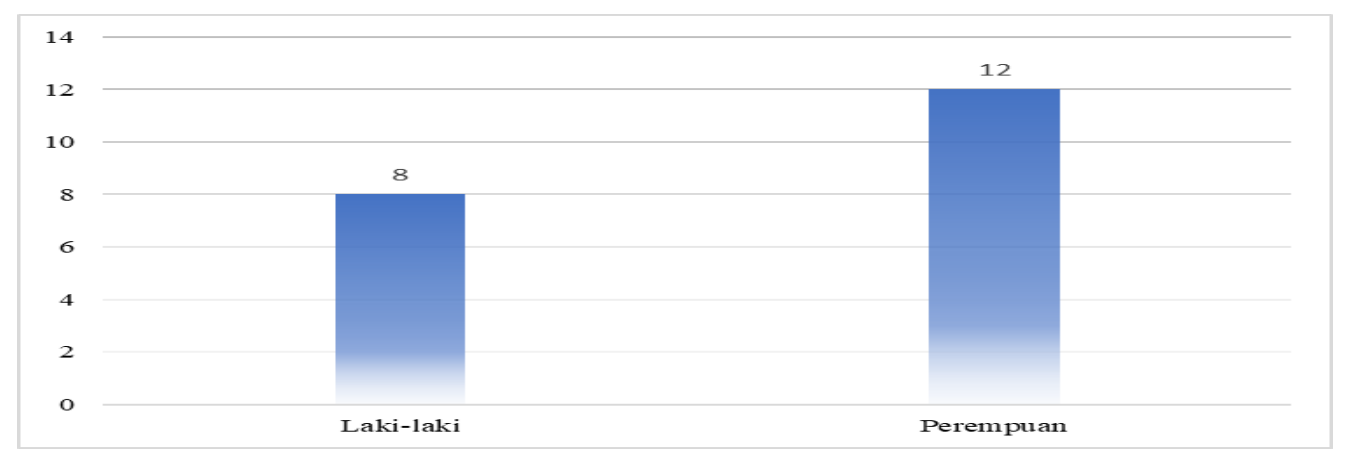


Berdasarkan hasil penelitian dan teori yang ada, dapat kita simpulkan bahwa jenis kelamin merupakan salah satu faktor dari kejadian asma bronkial. Hal tersebut dikarenakan volume dan kapasitas seluruh paru pada wanita kira-kira 20-25\% lebih kecil dari pada pria (Hidayat, 2008). Selain itu, adanya perbedaan pada paru dan ukuran jalan napas (airway) antara lakilaki dan perempuan juga mempengaruhi oksigenasi. Pada saat anak-anak, ukuran paru dan jalan napas pada anak laki-laki lebih kecil dibandingkan pada anak perempuan, sedangkan pada saat dewasa

\section{c. Faktor nutrisi}

Pada faktor nutrisi, pasien yang obesitas mengakibatkan penurunan ekspansi paru, gizi yang buruk menjadi anemia sehingga

\section{d. Faktor ekspansi paru}

Pada faktor ekspansi paru juga berpengaruh terhadap oksigen. Pengaturan posisi semi fowler dan fowler merupakan cara untuk meningkatnya ekspansi dada dan ventilasi paru serta menurunkan upaya

\section{e. Cara pemberian oksigen}

Cara pemberian oksigen juga berpengaruh terhadap oksigenasi dalam tubuh. Hal ini dikarenakan setiap jenis pemberian oksigen memiliki konsentrasi Fraksi ini. (usia $\geq 40$ tahun) ukuran paru dan jalan napas pada perempuan lebih kecil dibandingkan pada laki-laki, sehingga perempuan lebih berisiko terkena serangan asma pada saat dewasa ${ }^{[8]}$. Berdasarkan penelitian yang dilakukan oleh $C D C$ 's National Asthma Control Program Grantees (2013) prevalensi kejadian asma pada orang dewasa lebih banyak dialami oleh perempuan sebesar $10.7 \%$, sedangkan pada laki-laki sebesar $6.5 \%$ (CDC's National Asthma Control Program Grantee, 2013).

daya ikat oksigen berkurang, diet yang tinggi lemak menimbulkan arteriosklerosis (Mubarak, dkk, 2015).

pernapasan. Tujuan pengaturan posisi semi fowler dan fowler untuk membantu mengatasi masalah kesulitan bernapas dan mempertahankan kenyamanan dan memfasilitasi fungsi pernapasan pasien

Oksigen Inspirasi $\left(\mathrm{FiO}_{2}\right)$ yang berbeda (Morton, dkk, 2015). Peningkatan nilai saturasi berdasarkan cara pemberian oksigen terdapat pada gambar 6.6 di bawah 


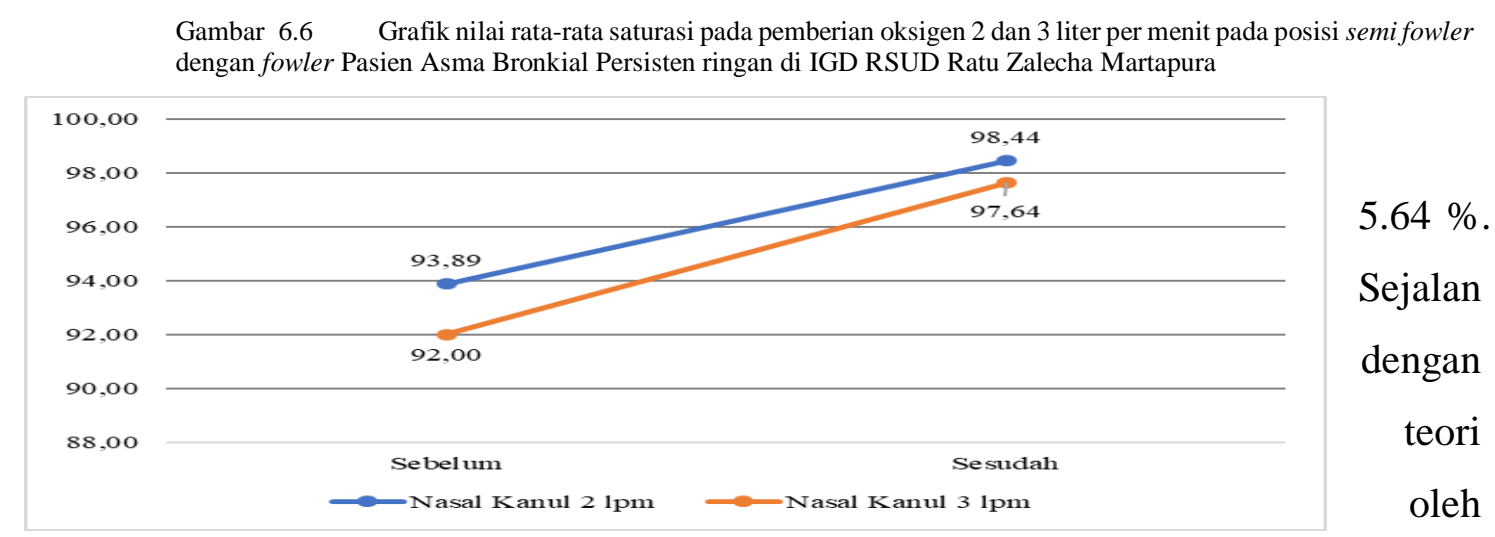

Berdasarkan hasil penelitian pada gambar 6.6 di atas, menunjukkan bahwa pemberian oksigen nasal kanul sebanyak 2 liter per menit dapat meningkatkan oksigen sekitar $4.56 \%$, sedangkan pada pemberian oksigen nasal kanul sebanyak 3 liter per menit dapat meningkatkan oksigen sekitar

\section{SIMPULAN}

Rata-rata saturasi oksigen dari 10 responden saat datang ke IGD sekitar $93.10 \%$ dan setelah pemberian terapi oksigen dengan posisi semi fowler sebesar $98.00 \%$.

Rata-rata saturasi oksigen dari 10 responden saat datang ke IGD sekitar

\section{DAFTAR RUJUKAN}

Balitbang Kemenkes RI.2007.Riset Kesehatan Dasar.Jakarta: Badan Penelitian dan Pengembangan Kesehatan Departemen Kesehatan, Republik Indonesia.

.2013.Riset

Kesehatan Dasar.Jakarta: Badan Penelitian dan Pengembangan
Morton, PG dkk (2012) bahwa setiap jenis pemberian oksigen memiliki konsentrasi Fraksi Oksigen Inspirasi (FiO2) yang berbeda sehingga semakin banyak jumlah oksigen yang diberikan, peningkatan saturasi oksigen semakin cepat (Morton, dkk, 2012).

$92.60 \%$ dan setelah pemberian terapi oksigen dengan posisi fowler sebesar $98.00 \%$.

Tidak ada perbedaan efektivitas pemberian oksigen pada posisi semi fowler dengan fowler terhadap perubahan saturasi pada pasien asma bronkial persisten ringan di IGD RSUD Ratu Zalecha Martapura.

Kesehatan Departemen Kesehatan, Republik Indonesia.

Cardona, V., et al.2011.Allergic diseases in the elderly.Clinical and Translational Allergy. (Diakses dari : http://www.ncbi.nlm.nih.gov pada hari Jumat, 28 April 2017 pukul 16.58 wita).

CDC's National Asthma Control Program Grantees.2013.Asthma Facts. United States of America : Department of 
Health and Human Services Centers for Disease Control and Prevention

Dahlan, S.2011.Statistik untuk Kedokteran dan Kesehatan Edisi 5.Jakarta: Salemba Medika

Doenges, M.E, et al, 2010.Nursing Care Plans Guidelines for Individualizing Client Care Across the Life Span Eight Edition.Philadelphia: F.A Davis Company

FitzGerald, J Mark et.al.2016.Global Strategy for Asthma Management and Preventation. (diakses dari: http://www.ginasthma.com pada hari Selasa, 1 November 2016 pukul 20.51 WITA)

Global Initiative for Asthma.2016.Global Strategy For Asthma Management And Prevention Updated 2016. (diakses dari: http://www.ginaasthma.org/ pada hari Jumat, 28 April 2017 pukul 19.09 wita)

Hidayat, A. Aziz.2008.Pengantar Kebutuhan Dasar Manusia Aplikasi Konsep dan Proses Keperawatan.Jakarta: Salemba Medika 2012.Pengantar

Kebutuhan Dasar Manusia Aplikasi Konsep dan Proses Keperawatan Buku 2.Jakarta: Salemba Medika

Kozier \& Erb's.2016.Fundamentals of Nursing Concepts, Process and Practice Tenth Edition.United States of America : Julie Levin Alexader

Morton, P.G, dkk.2012.Keperawatan Kritis Volume 1 Edisi 8.Jakarta: Penerbit Buku Kedokteran EGC

Mubarak, W.I. dkk.2015.Buku Ajar Ilmu Keperawatan Dasar Buku 2.Jakarta: Salemba Medika
Musliha.2010.Keperawatan Gawat Darurat.Yogyakarta: Nuha Medika

Nursalam.2015.Metodologi Penelitian Ilmu Keperawatan: Pendekatan Praktis.Jakarta: Salemba Medika

Pangestu, M dkk.2016.Hari Asma Sedunia: You Can Control Your Asthma.ISMKI Wilayah 1. (diakses dari : http://wilayah1.ismki.org/hari-asmasedunia-2016/. [1 November 2016 pukul 21.23 WITA]

Price, Sylvia A dan Lorraine M. Wilson.2006.Patofisiologi Konsep Klinis Proses-proses Penyakit Edisi 6.Jakarta : Penerbit Buku Kedokteran EGC

Setyohadi, B., dkk.2015.EIMED PAPDI Kegawatdaruratan Penyakit Dalam.Jakarta: Interna Publishing

Smeltzer, S.C et.al.2010.Brunner \& Suddart's Text Book of MedicalSurgical Nursing Twelfth Edition.Philadalphia: Lippincott Williams \& Wilkins

Sucahyono, W.2012.Identifikasi Penempatan Posisi terhadap Saturasi Oksigen pada Pasien Penyakit Paru Obstruksi Kronis di Ruang Dahlia Rumah Sakit Paru dr. Ario Wirawan Salatiga.Universitas Kristen Setya Wacana: Salatiga

Suparmi, Y, dkk.2008.Panduan Praktik Keperawatan Kebutuhan Dasar Manusia.Yogyakarta : PT.Citra Aji Parama

Tarwoto dan Watonah.2010.Kebutuhan Dasar Manusia dan Proses Keperawatan Edisi 3. Jakarta: Salemba Medika 
Wahyuningsih, N.2015.Pemberian Terapi Oksigen terhadap Perubahan Saturasi Oksigen Melalui Pemeriksaan Oksimetri pada Tn.K dengan Infark Miokard Akut (IMA) di ICVCU RSUD Dr. Moewardi Surakarta.Surakarta : Sekolah Tinggi Ilmu Kesehatan Kusuma Husa 